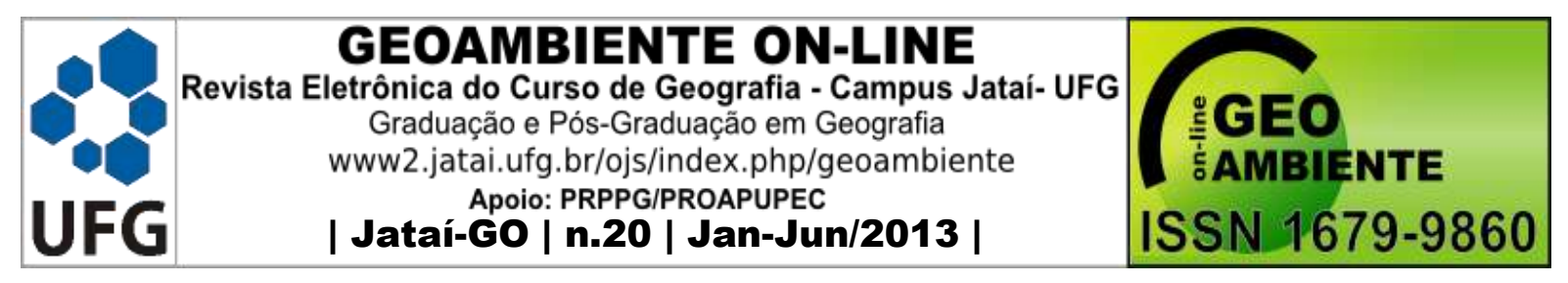

\title{
REGIÃO METROPOLITANA DE GOIÂNIA: ANÁLISE DA DISPOSIÇÃO ESPACIAL DOS RECURSOS FINANCEIROS PROVENIENTES DE CONVÊNIOS COM O GOVERNO FEDERAL
} ENTRE 2009 E $2011^{1}$

\author{
Juheina Lacerda Ribeiro Viana \\ (Universidade Federal de Goiás - Campus Goiânia - Instituto de Estudos Socioambientais - \\ juheinalacerda@hotmail.com)
}

\section{Resumo}

$\mathrm{O}$ artigo discute a distribuição de recursos provenientes de convênios entre os municípios da Região Metropolitana de Goiânia (RMG) e o Governo Federal por intermédio dos Ministérios da Saúde, Educação, Turismo e Cidades entre 2009 e 2011. Os convênios são analisados como mecanismos capazes de promover a integração metropolitana por meio da disponibilidade de serviços de interesse comum ou mesmo da execução de obras de infraestrutura. Para atingir os objetivos foi realizada análise bibliográfica e documental, coleta de dados secundários e mapeamento das informações. A distribuição espacial dos recursos nos permite concluir que, tal qual o padrão de dispersão da população e da infraestrutura urbana, os recursos provenientes são centralizados em municípios com maior demanda e também maior grau de burocratização das administrações municipais.

Palavras-chave: Região Metropolitana de Goiânia; Convênios; Ministérios; Recursos.

\author{
Abstract \\ METROPOLITAN AREA OF GOIÂNIA: ANALYSIS OF THE SPATIAL \\ DISPOSITION OF THE FINANCIAL RESOURCES COMING FROM \\ AGREEMENTS WITH THE FEDERAL GOVERNMENT IN THE PERIOD 2009-2011
}

\footnotetext{
Artigo recebido para publicação em 07 de Janeiro de 2013

Artigo aprovado para publicação em 08 de Maio de 2013

${ }^{1} \mathrm{O}$ artigo contém resultados parciais do projeto "Espacialização e análise dos impactos das transferências de recursos constitucionais (estadual e federal), geração de receita própria e transferências diretas para a economia dos municípios da Região Metropolitana de Goiânia, entre 2008 e 2011" financiado pela Fundação de Amparo à Pesquisa do Estado de Goiás (FAPEG).
} 


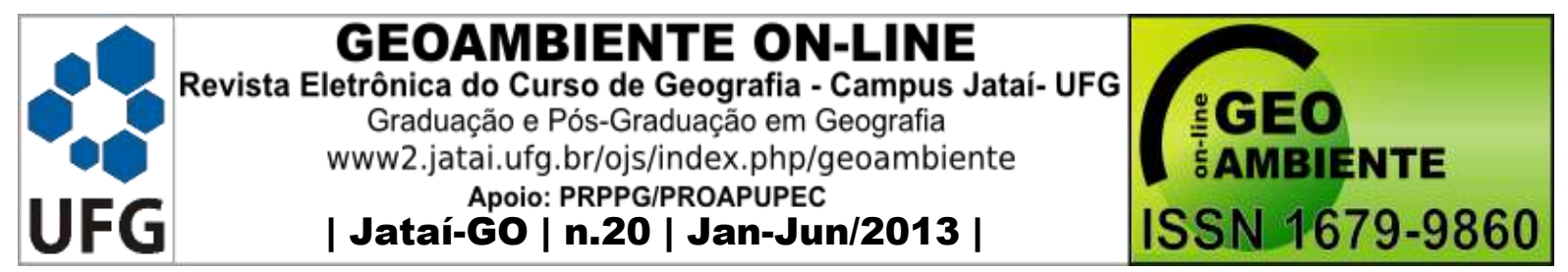

The article discuss the distribution of the resources derived from agreements between the cities of the Metropolitan Region of Goiânia (RMG) and the federal government through the Ministries of Health, Education, Tourism and Cities between 2009 and 2011. The agreements are analyzed as mechanisms able to promote the metropolitan integration by the availability of mutual interest services or even the execution of works of infrastructure. For reaching the goals were made documental and bibliographic analysis, secondary data collection and mapping of the informations. The spatial distribution of the resources permits to accomplish that, even as the dispersal pattern of the population and the urban infrastructure, the resources derived are centralized in cities with major needings and also major degree of bureaucratization of the cities administration.

Keywords: Metropolitan Region of Goiânia; Covenants; Ministries; Resources.

\section{Resumen}

\section{ÁREA METROPOLITANA DE GOIÂNIA: UN ANÁLISIS DE LA DISPOSICIÓN ESPACIAL DE LOS RECURSOS FINANCIEROS DE ACUERDOS FIRMADOS CON EL GOBIERNO FEDERAL ENTRE 2009 Y 2011}

El artículo analiza la distribución de los fondos provenientes de los acuerdos entre los municipios de la Región Metropolitana de Goiânia (RMG) y el Gobierno Federal a través de los Ministerios de Salud, Educación, Turismo y Ciudades entre 2009 y 2011. Los acuerdos se integran como mecanismos capaces de promover la integración metropolitana a través de la disponibilidad de los servicios de interés común o la ejecución de obras de infraestructura. Para lograr los objetivos se realizaron análisis bibliográfico y documental, la recogida de datos secundarios y el mapeo de informaciones. La distribución espacial de los recursos nos permite concluir que, al igual que el patrón de dispersión de la población y la infraestructura urbana, los recursos provenientes se centralizan en los municipios con mayor demanda y mayor grado de burocratización de las administraciones municipales.

Palabras claves: Región Metropolitana de Goiânia; Convenios; Ministerios; Recursos.

\section{INTRODUÇÃO}

O trabalho tem o propósito de analisar a dinâmica de distribuição de recursos advindos de convênios firmados entre o Governo Federal e os municípios da Região Metropolitana de Goiânia (RMG), entre 2009 e 2011. Para atingir os objetivos propostos foi necessário 


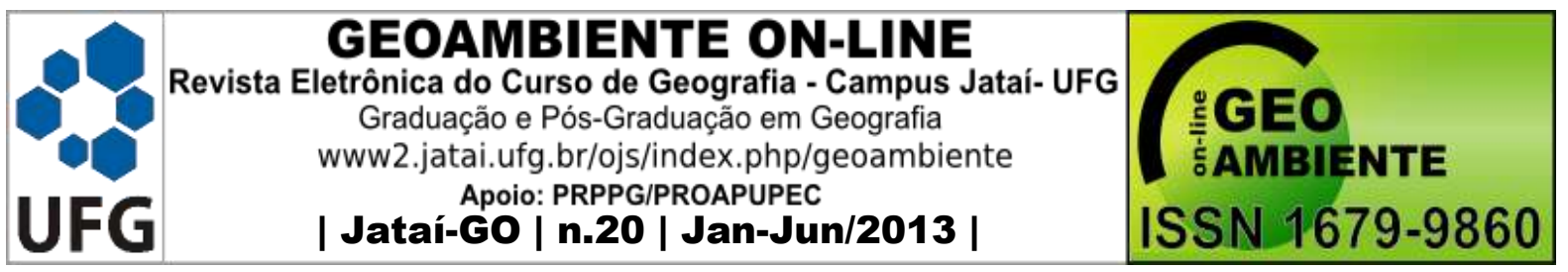

compreender a composição das receitas municipais, as demandas por infraestrutura urbana e serviços espacializadas nos municípios e posteriormente, os convênios firmados.

As receitas orçamentárias isoladas não conseguem atender às demandas existentes nos municípios, em função do que Lanzana (2010), destacou como rigidez orçamentária. Essa tendência ocorre, sobretudo, nos municípios de menor peso demográfico (em função do modelo de distribuição dos recursos públicos) e com economia pouco dinâmica. Sendo assim, os convênios tornam-se importante ferramenta de ação na produção do espaço no território nacional. Por meio dessa análise podemos observar a funcionalidade desse instrumento na configuração socioespacial dos municípios, uma vez que, os convênios celebrados com os ministérios selecionados são de fundamental importância para a constituição da "Justiça Distributiva Territorial", da forma como definiu Harvey (1980). ${ }^{2}$ A análise partirá da perspectiva de Lefebvre (2009) ao conceber que para a pesquisa de processos decorrentes do espaço urbano é necessário partir de diferentes níveis de análise (Estado, Instituições e Indivíduos), e como esses níveis se correlacionam. Portanto é importante compreender a interconexão das ações das três esferas governamentais brasileiras (União, Estados e Municípios) no que concerne a distribuição de recursos públicos.

\section{DINÂMICA METROPOLITANA: O CASO DA REGIÃO METROPOLITANA DE GOIÂNIA}

O estudo realizado se desenvolve em escala regional ao buscar a compreensão das dinâmicas socioeconômicas relacionadas à RMG, ressaltando elementos que sejam capazes de identificar a ineficiência dos arranjos institucionais frente às demandas da população. ${ }^{3}$

As Regiões Metropolitanas (RMs) foram instituídas em 1973 com a criação de 8 RMs. ${ }^{4}$ Um de seus objetivos principais era viabilizar um plano de desenvolvimento integrado

\footnotetext{
${ }^{2}$ Harvey (1980, p. 86) destaca nove necessidades básicas da população urbana que permanecem constante no tempo, dentre elas, a Habitação, Cuidados Médicos, Educação e Oportunidades de Lazer. Correlacionando a análise do autor com o atual momento político administrativo no Brasil nota-se que através dos convênios os Ministérios selecionados agem de forma a prover a Justiça Distributiva Territorial, por exemplo: do Ministério das Cidades que proporciona desenvolvimento de projetos voltados para habitação popular. Ministério da Saúde que volta sua atenção para a aquisição de equipamentos e melhorias na infraestrutura voltados a oferta de saúde pública, assim como o Ministério da Educação que age de forma semelhante com os serviços educacionais. Por fim, o Ministério do Turismo que por meio de reformas e construção equipamentos de lazer e eventos culturais proporciona momentos de lazer à população.

${ }^{3}$ A importância da utilização do recorte regional no estudo realizado decorre do fato de que os equipamentos e serviços espacializados em determinado município podem ser utilizados pelos demais, pois no contexto metropolitano, ambos estão integrados.
} 


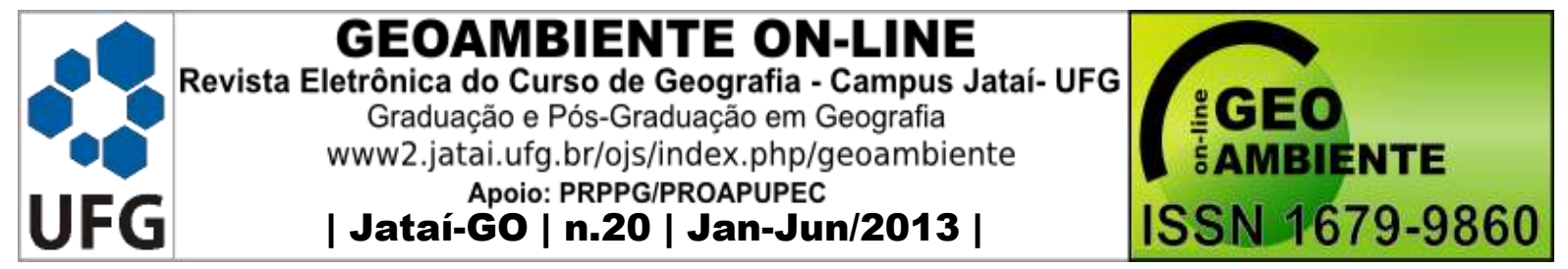

que contemplasse todos os municípios pertencentes às regiões, promovendo um desenvolvimento econômico e social integrado. Além disso, os municípios teriam preferências de investimentos e empréstimos em relação aos demais, junto à União. Após a promulgação da constituição de 1988 a responsabilidade pela criação das RMs passou a ser controlada pelos Estados. Com isso, foram criadas várias outras regiões, totalizando 37 RMs e três regiões integradas de desenvolvimento (Ride) em 2011, segundo estudos publicados pelo Instituto de Pesquisa Econômica Aplicada (IPEA, 2011).

A Região Metropolitana de Goiânia (RMG) foi institucionalizada pela lei complementar número 27, de 30 de dezembro de 1999, e modificada pela lei complementar número 78, de 25 de março de 2010, que incluiu sete municípios passando a ser composta por 20 municípios cujo padrão demográfico, espacial e social é bastante heterogêneo. A figura 1 apresenta o padrão demográfico metropolitano. Em 2000, a RMG possuía população total de 1.743.297, passando para 2.173.006 habitantes em 2010, representando 34,83\% do total do Estado (IBGE, 2011). Analisando a dinâmica demográfica contemporânea, percebe-se maior incremento relativo de municípios como Goianira (1,82\%), Senador Canedo $(1,59 \%)$ e Santo Antônio de Goiás (1,51\%). Goiânia $(1,19 \%)$ foi o sétimo município da RMG com menor crescimento relativo e sua representação no total da população da RMG passou de 62,69\% em 2000 para 59,91\% em 2010.

Esse perfil se justifica pela valorização fundiária crescente na capital e à incorporação de estoques de áreas rurais, principalmente nos municípios limítrofes para saldar as demandas por habitação que não são absorvidas pelo núcleo metropolitano, ao favorecer, assim, os movimentos migratórios para estes locais, como indicou Arrais et al.(2012).

\footnotetext{
${ }^{4}$ Ficam estabelecidas pela Lei Complementar ${ }^{\circ} 14$, de 8 de Junho de 1973, as regiões metropolitanas de São Paulo, Belo Horizonte, Porto Alegre, Recife, Salvador, Curitiba, Belém e Fortaleza. Fonte: http://www.planalto.gov.br/ccivil_03/leis/lcp/Lcp14.htm
} 


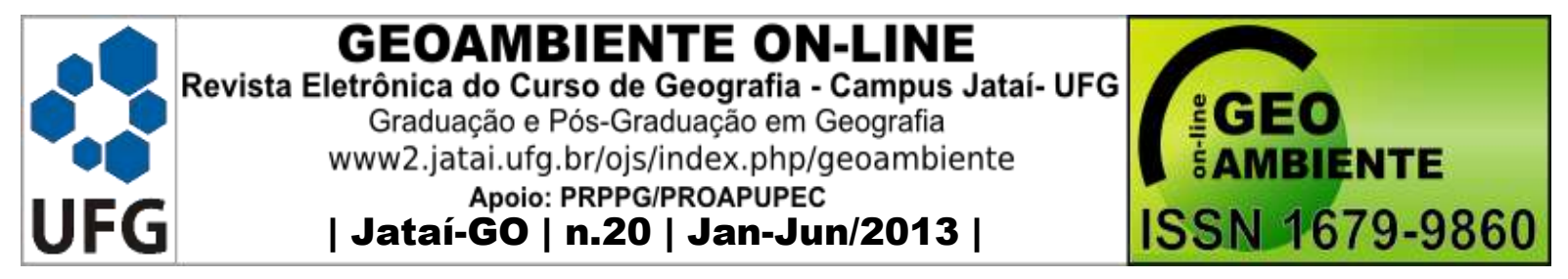

Figura 1 . Região Metropolitana de Goiânia: população e densidade demográfica, 2010.

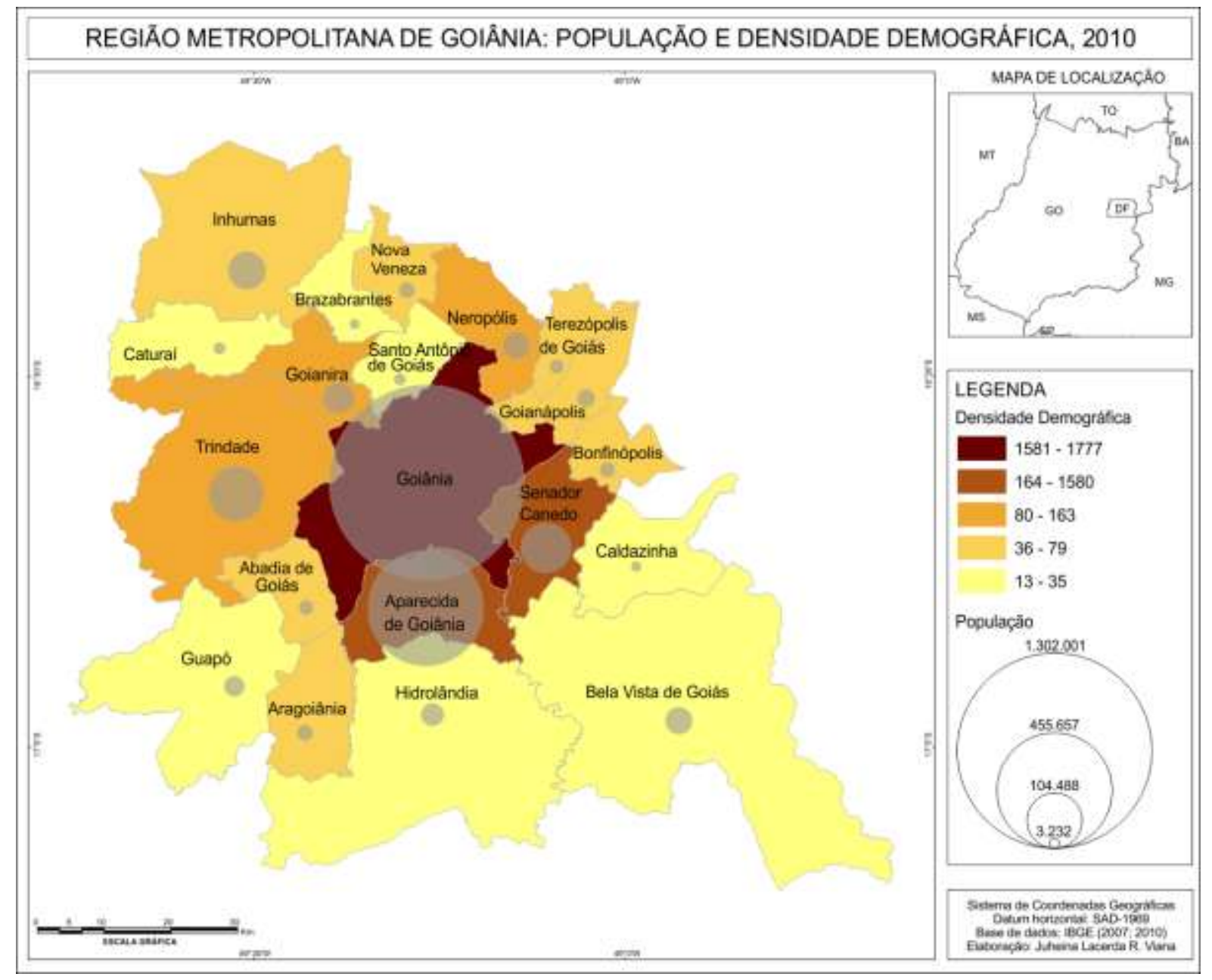

\section{COMPOSIÇÃO DAS RECEITAS MUNICIPAIS}

Para compreender as especificidades da RMG é preciso levar em conta sua dinâmica econômica do ponto de vista dos recursos disponíveis para a gestão municipal e a polarização exercida pelo núcleo metropolitano. Na medida em que se centralizam serviços e equipamentos consequentemente se polarizam os recursos, como se observa a composição dos recursos municipais: 1 . as transferências federais analisadas variam de acordo com o padrão demográfico municipal; 2. as transferências estaduais reverberam o perfil econômico municipal, ao refletir a disposição espacial dos equipamentos públicos e privados, assim como o de veículos automotores; 3. As receitas tributárias são dispostas sobre o uso do solo municipal, com a finalidade de habitação ou desenvolvimento de serviços de qualquer natureza; 4. os fundos para manutenção de serviços básicos denotam como a centralização dos equipamentos públicos e como a migração pendular para uso desses são funcionais para 


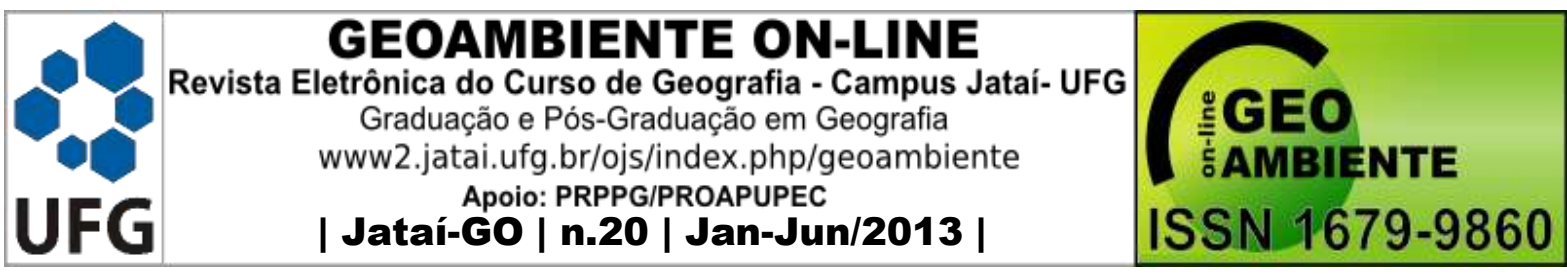

financiamento de tais serviços. A figura 2 indica as principais receitas dos municípios da RMG.

Figura 2. Constituição das receitas municipais.

\begin{tabular}{|c|c|c|c|c|c|c|c|c|c|c|c|c|c|c|c|c|c|}
\hline \multicolumn{18}{|c|}{ ORIGEM DAS PRINCIPAIS RECEITAS MUNICIPAIS } \\
\hline \multicolumn{9}{|c|}{$\begin{array}{c}\text { TRANSFERÊNCIAS } \\
\text { INTERGOVERNAMENTAIS }\end{array}$} & \multirow{2}{*}{\multicolumn{6}{|c|}{$\begin{array}{l}\text { Receitas } \\
\text { Tributárias }\end{array}$}} & \multirow{2}{*}{\multicolumn{3}{|c|}{ FUNDOS }} \\
\hline \multicolumn{5}{|c|}{ Federais } & \multicolumn{4}{|c|}{ Estaduais } & & & & & & & & & \\
\hline 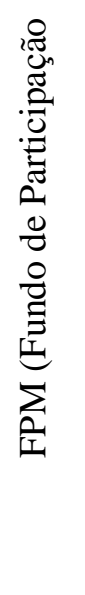 & 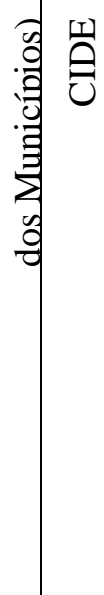 & 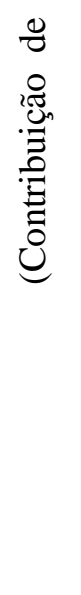 & 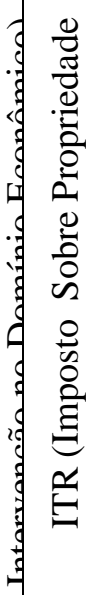 & 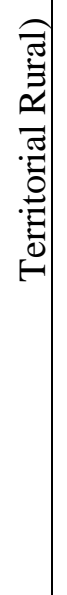 & $\sum_{\varrho}^{\mathscr{L}}$ & 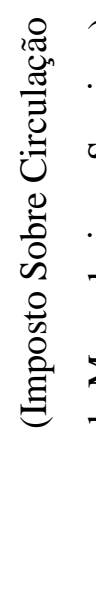 & 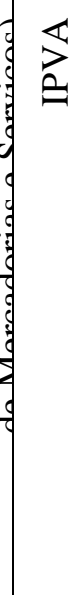 & 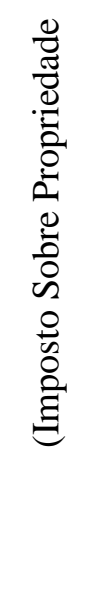 & 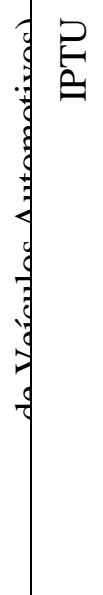 & 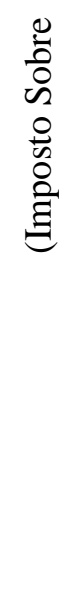 & 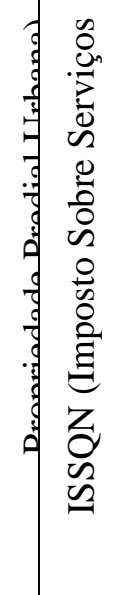 & 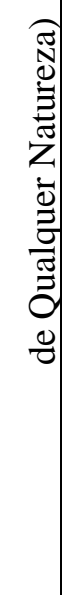 & $\vec{p}$ & $\begin{array}{l}0 \\
0 \\
0 \\
0 \\
0 \\
0 \\
0 \\
0 \\
0 \\
0 \\
0 \\
0 \\
0 \\
0 \\
0 \\
0 \\
0 \\
0 \\
0 \\
0 \\
0 \\
0 \\
0\end{array}$ & 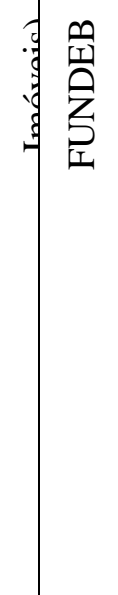 & 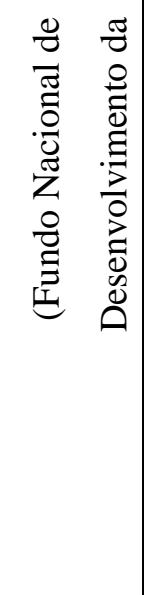 & 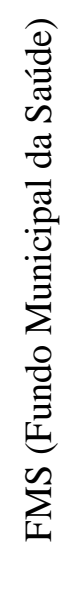 \\
\hline
\end{tabular}

Fonte: Tesouro Nacional, Tribunal de Contas dos Municípios - GO (2010).

Esses recursos são utilizados para a manutenção das atividades básicas dos municípios, como despesas com saúde, educação, pagamento de funcionários e realização de obras de infraestrutura urbana, como já mencionado por Lanzana (2010) ao analisar a política fiscal nas esferas Federal, Estadual e Municipal. É importante destacar que tais recursos não podem ser utilizados de forma livre pelos municípios, exceção para as receitas tributárias. Do total das receitas arrecadadas pelo executivo na RMG em 2010, Goiânia concentrou 69,80\%, enquanto municípios como Brazabrantes, Caturaí e Caldazinha concentraram juntos 0,98\% das receitas arrecadadas e distribuídas na região (TCM - GO/2010). ${ }^{5}$ Esse padrão desigual de arrecadação é resultado da posição ocupada pela capital, com intensa concentração demográfica, valorização fundiária e concentração dos equipamentos de serviços (públicos e privados).

\footnotetext{
${ }^{5}$ As receitas do executivo são formadas por impostos e taxas recolhidos diretamente pela prefeitura e transferências de recursos do governo estadual e federal, por meio do repasse de parte dos impostos que recebem.
} 


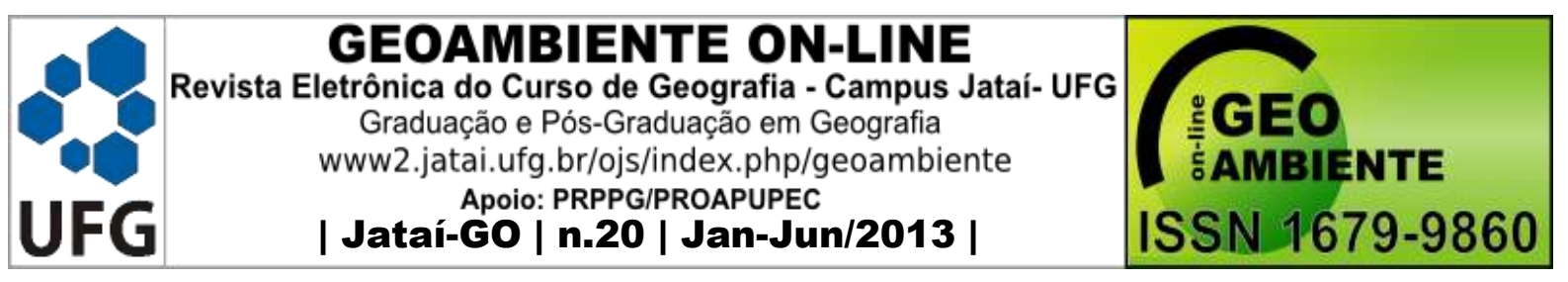

A figura 3 demonstra a centralidade de Goiânia em relação aos demais municípios que compõem a RMG por meio de sua concentração equipamentos de serviços básicos como loterias, agências bancárias, hospitais e escolas. Dos 1.787 equipamentos verificados, 65,47\% se concentram na capital. Isso motiva o deslocamento de pessoas em busca de serviços que não são oferecidos nos municípios onde residem, ou quando estes serviços não atendem as demandas da população. Em 12 municípios com padrão demográfico inferior a 11 mil habitantes, a presença de loterias, agências bancárias e hospitais se restringem a um equipamento ou mesmo nenhum. Dentre estes, destacam-se Caldazinha e Caturaí, que de modo geral possuem apenas seis e oito equipamentos de uso coletivo, respectivamente.

Figura 3. Região Metropolitana de Goiânia: distribuição dos equipamentos de serviço, 2010.

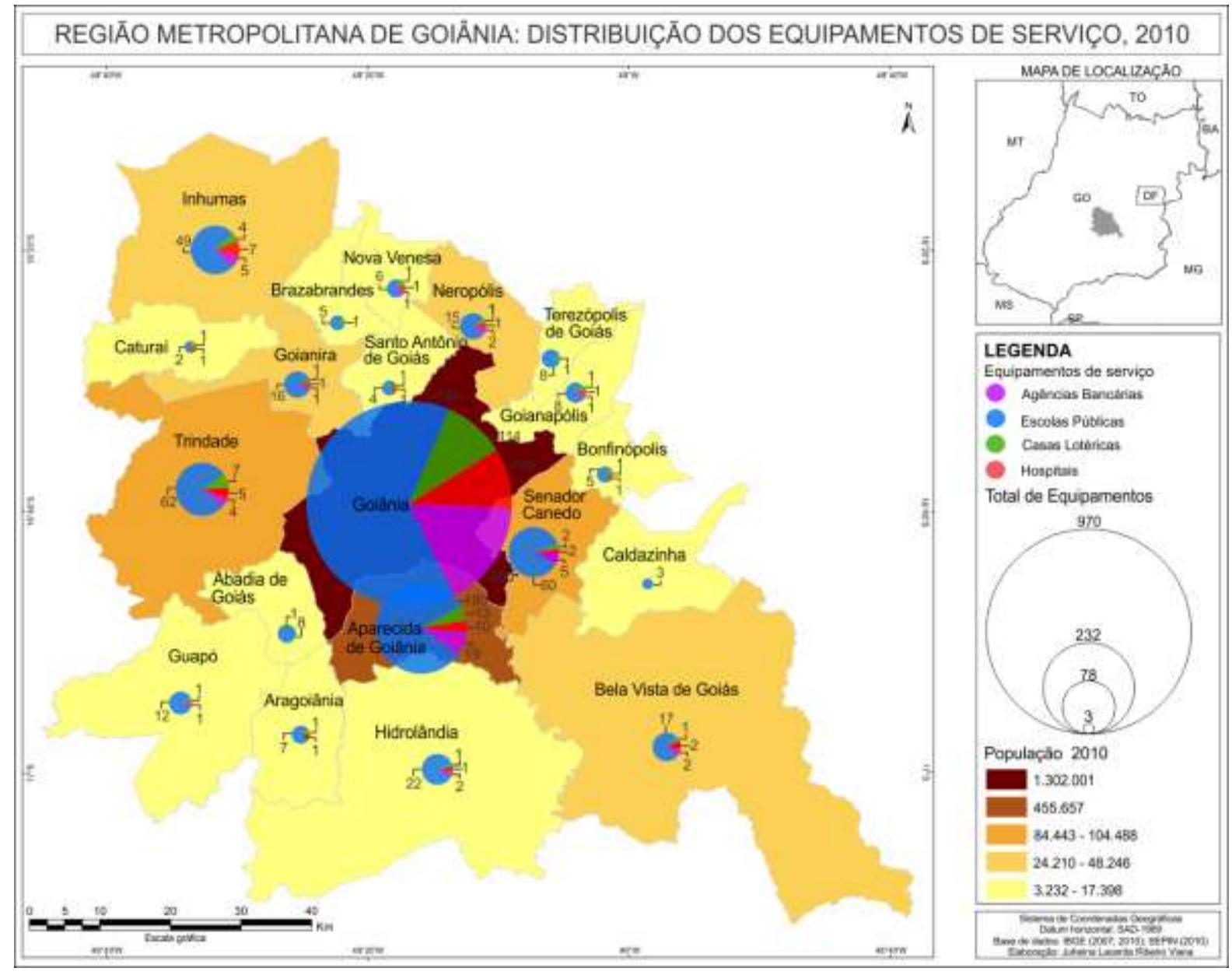

Dentre estes equipamentos, o ensino, é o único de uso diário que é ofertado em todos os municípios, conforme previsto na Constituição Federativa de 1988. Entretanto, esse serviço 


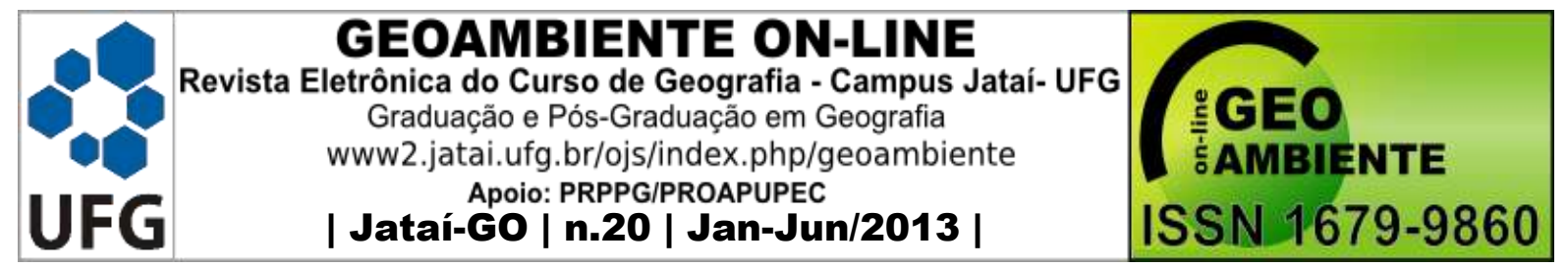

não atende as demandas de parte da população, principalmente porque grande parte das instituições de ensino básico, superior, técnico, profissional, público ou privado, se concentram na capital, fator que motiva a mobilidade para o estudo.

Além da prestação de serviços, outros importantes elementos devem ser considerados, como exemplo, a distribuição de infraestrutura, entre os municípios. Num contexto regional, investimentos em infraestrutura urbana são fundamentais para um crescimento econômico homogêneo entre os municípios, atraindo população e investimentos financeiros, gerando e/ou aquecendo os fluxos econômicos entre os municípios.

A figura 4 informa a porcentagem de residências com tratamento de esgoto, água tratada, coleta de lixo e energia elétrica. O serviço mais ineficiente dentre os contemplados é o serviço de tratamento de esgoto, ausente em 10 dos 20 municípios da RMG, e quando é disponível atende principalmente os municípios que possuem faixas populacionais superiores a 11 mil habitantes. Os demais tipos de serviços são ofertados em todos os municípios, mas não são oferecidos a todos os domicílios. Goiânia concentra maior infraestrutura, se comparada aos demais municípios, sua média entre os equipamentos contemplados na análise é de 79,70\% (IBGE, 2010). Por outro lado, Caldazinha é o município mais carente em infraestrutura, atendendo uma média de $42,58 \%$ da população, seguido por Hidrolândia (44,23\%), Aragoiânia (46,94\%) e Caturaí (48,04\%).

Ao se observar tal padrão, percebe-se que as disparidades geradas no campo políticoeconômico são reverberadas diretamente no cotidiano da população, haja visto a heterogeneidade na prestação de serviços básicos à população dos municípios que compõe a RMG. A respeito dessa dinâmica Garson (2009) analisa a atual conjuntura econômica dos municípios problematizando a rigidez orçamentária, pois esta "rigidez" impossibilita que os governos municipais arquem com compromissos de grande impacto. Segundo ele:

A rigidez da despesa de todos os níveis de governo, a magnitude dos investimentos requeridos e a dimensão extraterritorial que têm as ações de desenvolvimento urbano tornam indispensável a articulação de ações entre os três níveis de governo e o setor privado, de forma a atender as demandas da sociedade. (GARSON, 2009, p. 20) 


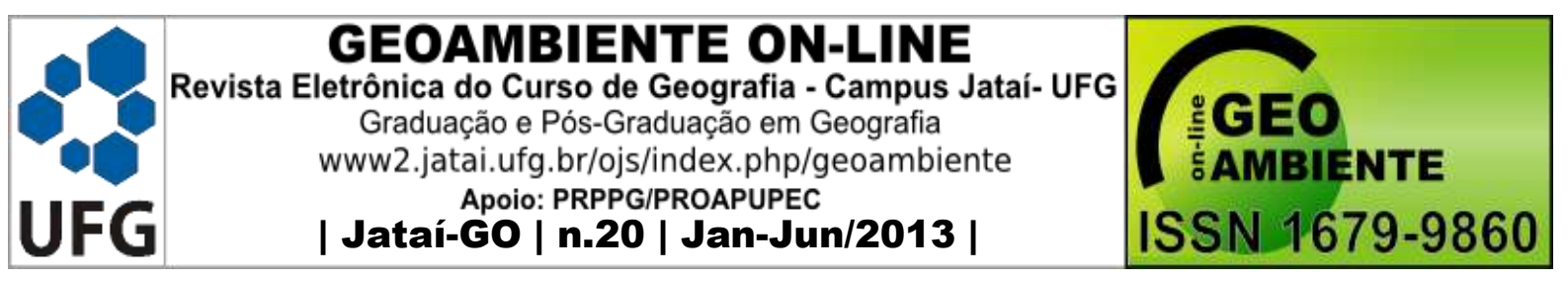

Com base na tendência apresentada é possível concluir que as esferas governamentais tem a necessidade de buscar outros tipos de recursos que os auxiliem na realização de obras de infraestrutura urbana, disponibilidade de serviços básicos (educação e saúde) ou na realização de eventos festivos, como o "Arraiá do Cerrado" realizado em Nerópolis anualmente.

Figura 4. Região Metropolitana de Goiânia: infraestrutura básica, 2010.

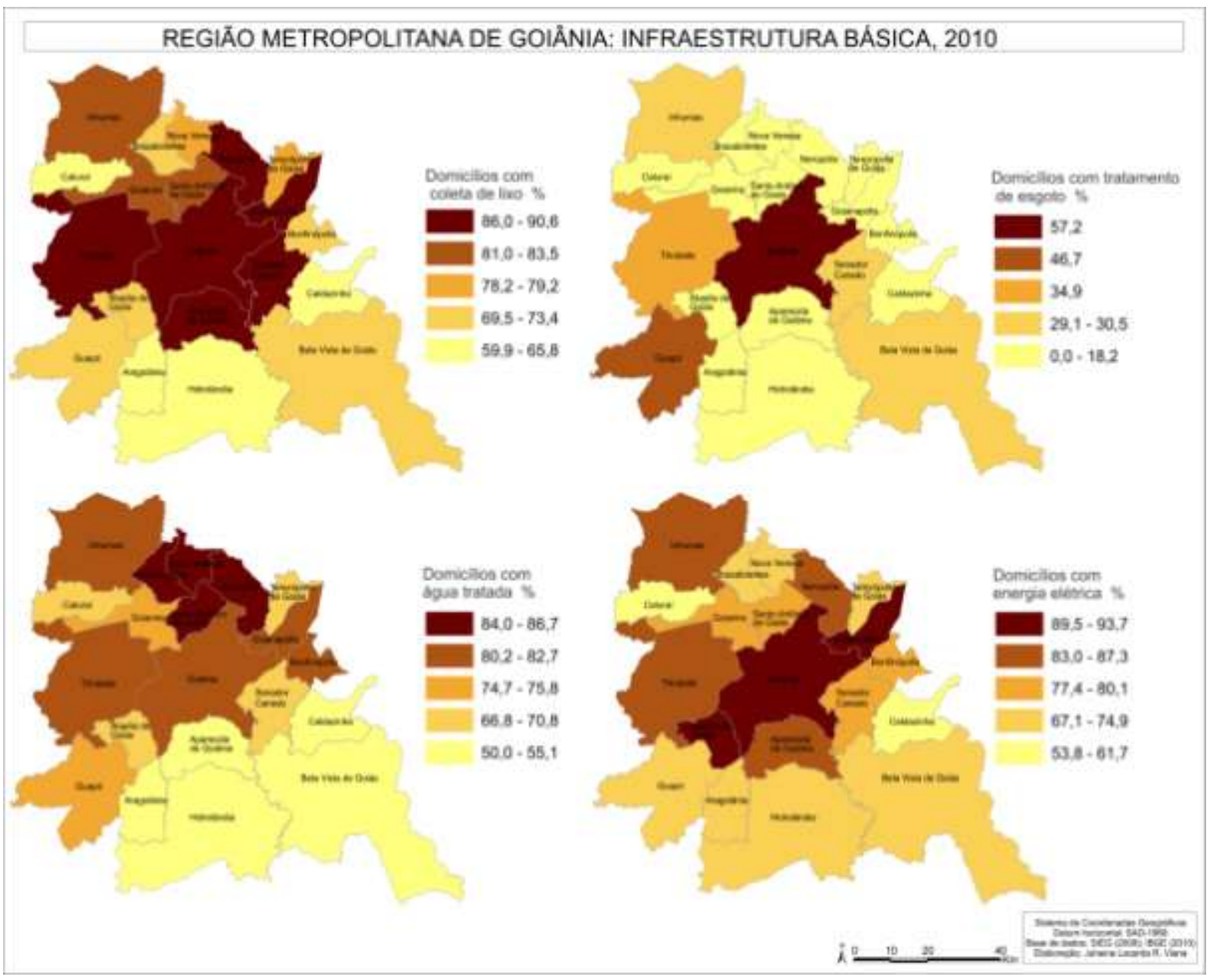

\section{CONVÊNIOS: DISPOSIÇÃO ESPACIAL DOS RECURSOS}

No Brasil, após a constituição federativa de 1988 no discurso de descentralização de poder e recursos foram definidos três entes autônomos: União, Estados e Municípios. Entretanto, dadas ás heterogeneidades socioeconômicas regionais e intrarregionais a autonomia não ganhou caráter efetivo em todo território nacional. 


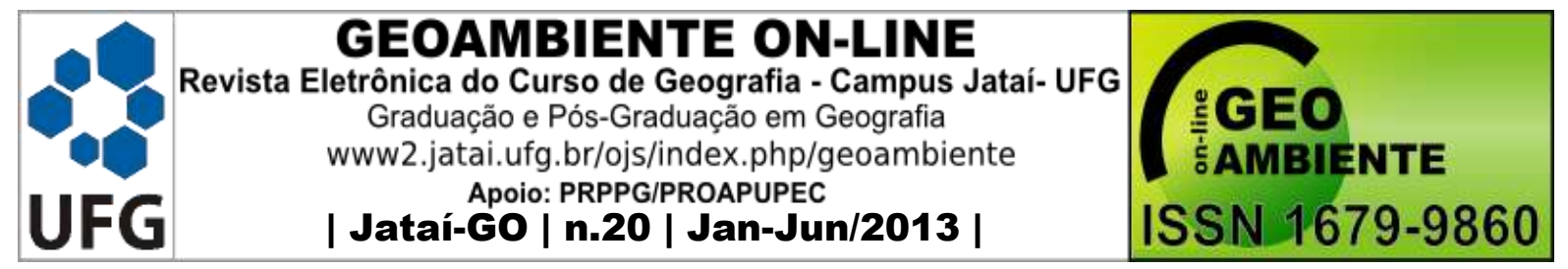

Dessa forma, para analise da organização espacial torna-se necessário conceber as relações político-administrativas das esferas governamentais, assim como observou Corrêa (2011), ao dizer que:

Dada a complexidade da ação do Estado, envolvendo múltiplos papéis, com pesos distintos no tempo e espaço, torna-se necessário que novos estudos sejam realizados, tanto nas esferas federal e estadual como na municipal. Estas esferas ou escalas espaciais podem implicar diferentes ações que, no entanto, não devem estar desconectadas. (CORRÊA, 2011, p.46)

Nessa perspectiva, o município exerce importante funcionalidade na conexão das três esferas governamentais, de modo que, todas as ações, independente da esfera, se materializam no município, como já afirmado por Arrais (2008). Em função dos orçamentos enrijecidos, os convênios representam uma das alternativas para que através de um objetivo comum os gestores municipais possam realizar obras ou serviços que sejam capazes de atender demandas do desenvolvimento municipal, sendo importante mecanismo para a produção do espaço urbano. Na Portaria Interministerial número 507, de 24 de novembro de 2011, o convênio é definido como:

Acordo ou ajuste que discipline a transferência de recursos financeiros de dotações consignadas nos Orçamentos Fiscais e Seguridade Social da União e tenha como partícipe, de um lado, órgão ou entidade da administração pública federal, direta ou indireta, e, de outro lado, órgão ou entidade da administração pública estadual, do Distrito Federal ou municipal, direta ou indireta, consórcios públicos, ou ainda, entidades privadas sem fins lucrativos, visando à execução de programa de governo, envolvendo a realização de projeto, atividade, serviço, aquisição de bens ou evento de interesse recíproco, em regime de mútua cooperação. (BRASIL, 2011). ${ }^{6}$

Os convênios estão contemplados inicialmente pela Lei $n^{\circ}$ 8.666, de 21 de junho de 1993, e podem ser consolidados por meio de parcerias entre as três esferas de governo e com o setor privado. Para a sua realização é necessário que haja um objetivo comum, mediante a apresentação da documentação e do plano de trabalho junto ao Governo Federal.

\footnotetext{
${ }^{6}$ Como consta no Artigo 241 da Constituição Federal: “A União, os Estados, o Distrito Federal e os Municípios disciplinarão por meio de lei os consórcios públicos e os convênios de cooperação entre os entes federados, autorizando a gestão associada de serviços públicos, bem como a transferência total ou parcial de encargos, serviços, pessoal e bens essenciais à continuidade dos serviços transferidos”. (BRASIL, 1988)
} 


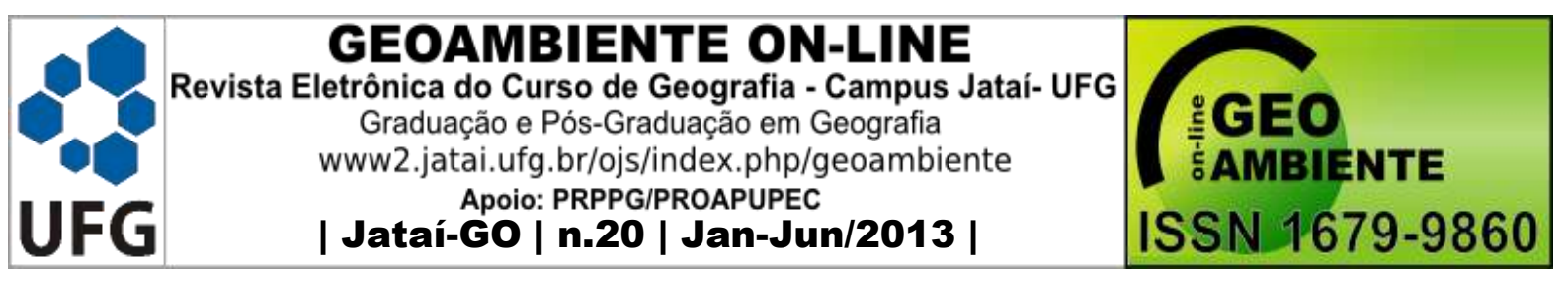

Foram selecionados para análise os convênios firmados com o Ministério das Cidades, Ministério da Saúde, Ministério da Educação e Ministério do Turismo, tendo em vista os valores destinados a essas esferas administrativas. Os valores repassados entre 2009 e 2011 foram destinados principalmente para obras de infraestrutura urbana, cujo destino mais recorrente nos municípios foi pavimentação asfáltica, construção de galerias pluviais e implantação de sistemas de drenagem. Em Goiânia além da realização desses serviços, foram realizados planos habitacionais, construção de unidades habitacionais e ampliação do sistema de esgotamento sanitário. As figuras 5 e 6 informam o número de convênios firmados em 2009 e 2011 com os Ministérios selecionados e os valores destinados a cada município da RMG.

Figura 5: Região Metropolitana de Goiânia: Repasses realizados por meio de convênios com os

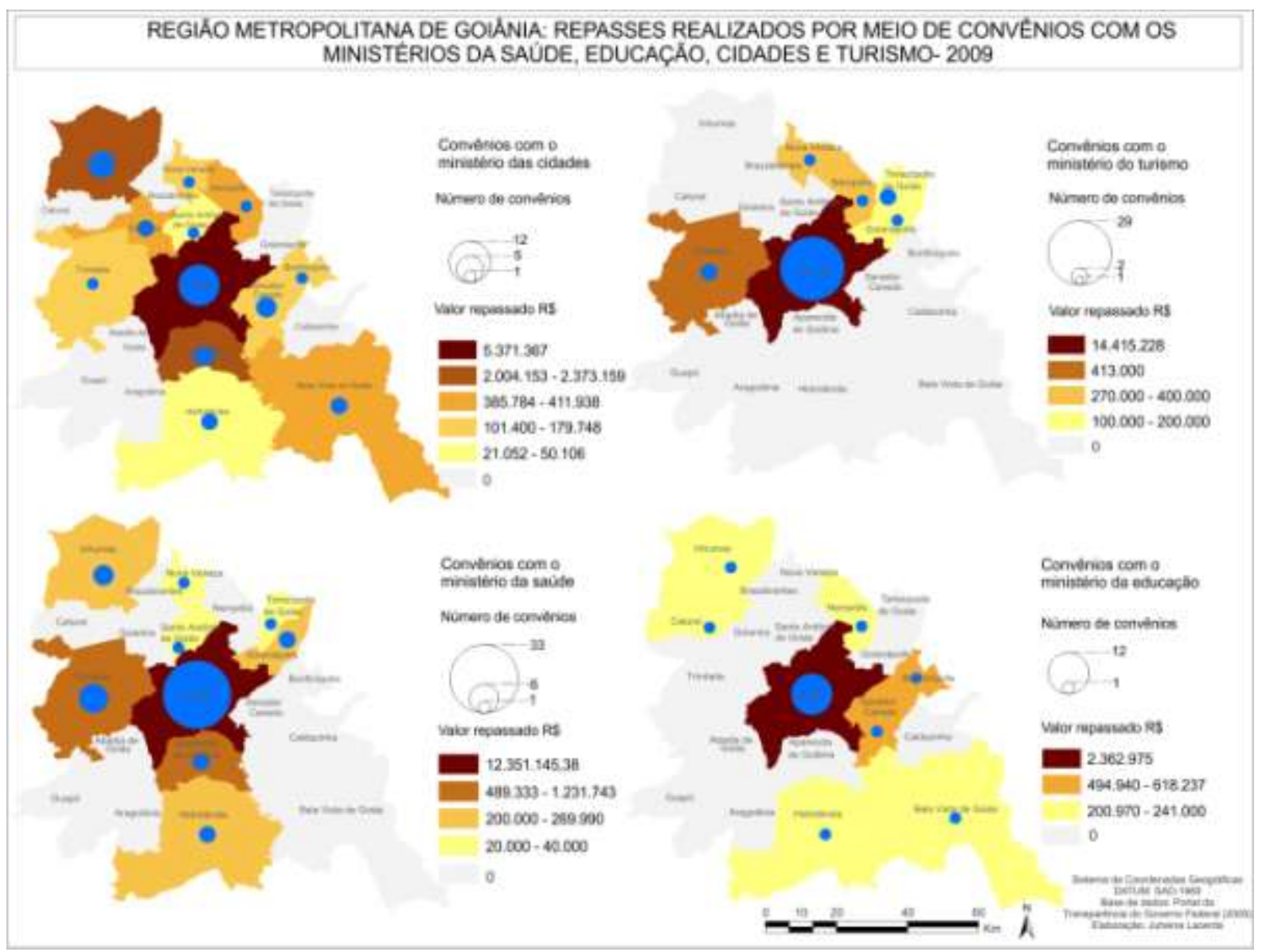

Ministérios da Saúde, Educação, Cidades e Turismo, 2009. 


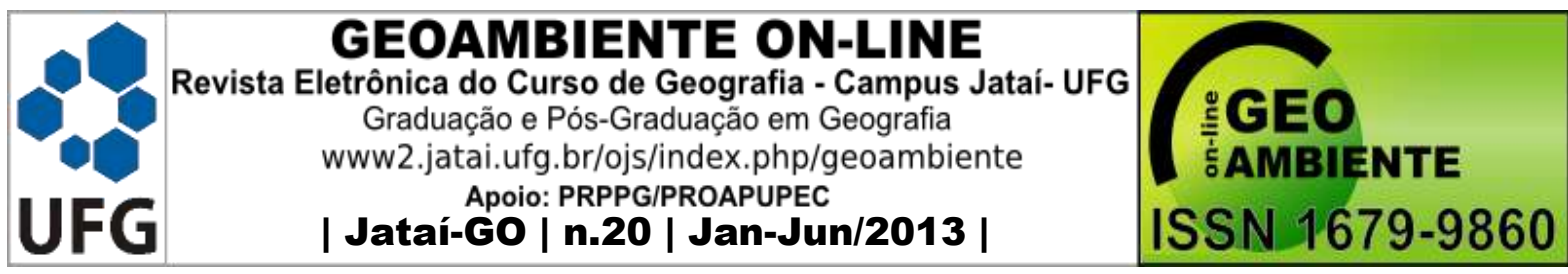

Figura 6. Região Metropolitana de Goiânia: Repasses realizados por meio de convênios com os

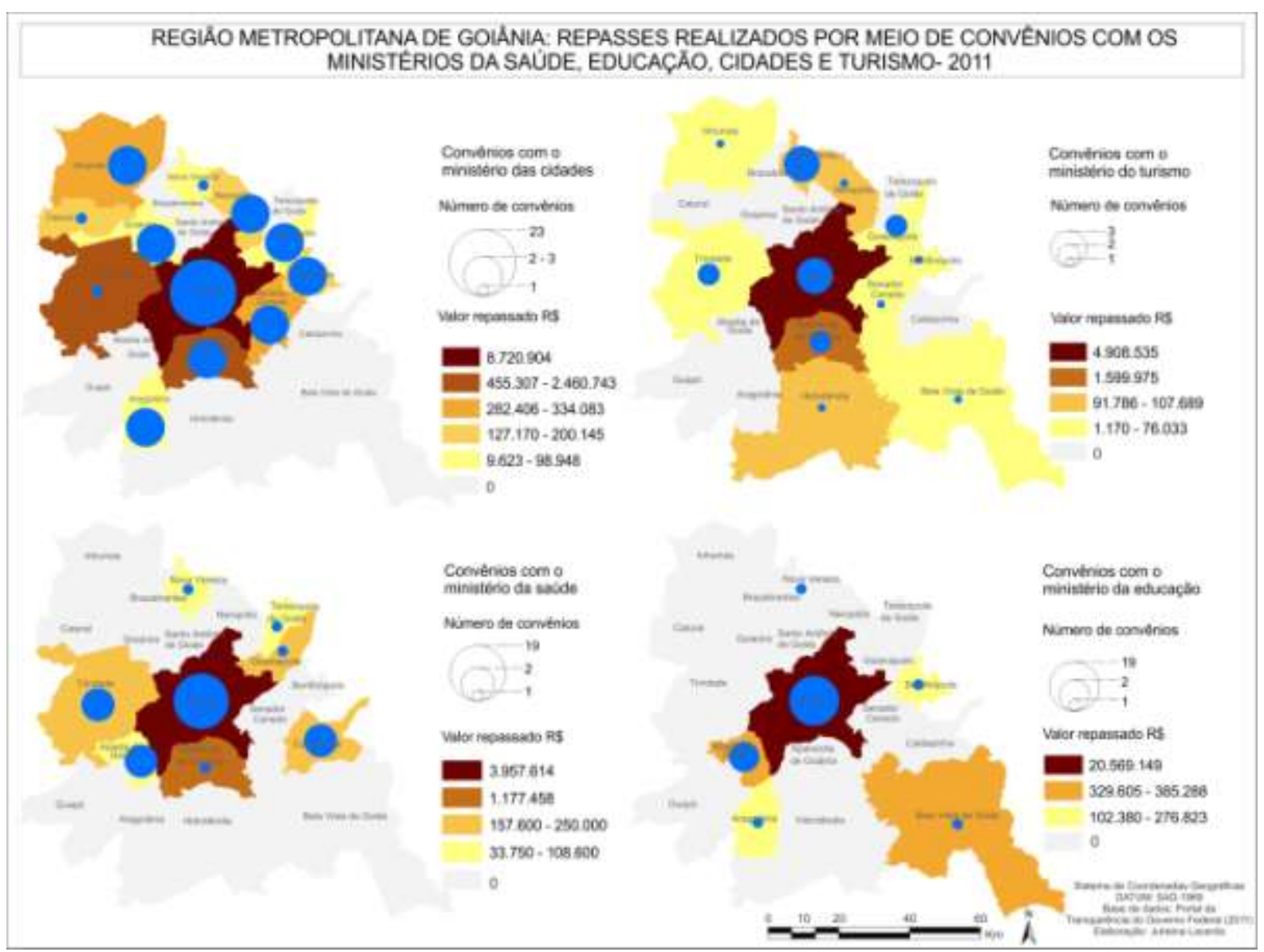

Ministérios da Saúde, Educação, Cidades e Turismo, 2011.

Em 2009 a RMG foi contemplada com R\$ 11.499.375,77, repassados ao Ministério das Cidades para a realização das obras e serviços solicitados. Os maiores repasses foram destinados a Goiânia, Aparecida de Goiânia e Inhumas, respectivamente. Outros nove municípios também firmaram convênios com esse Ministério, somando um repasse total de R\$ 1.750.694,39. Em 2010 os valores repassados por meio deste Ministério tiveram os maiores repasses no período analisado. O valor total repassado foi de $\mathrm{R} \$ 32.517 .649,06$, e assim como em 2009 os maiores valores foram destinados aos municípios anteriormente mencionados. Goiânia concentrou $\mathrm{R} \$ 27.796 .781,63$ para a realização de pavimentação asfáltica, construção de meio fio, e construção de 1.600 unidades habitacionais. Assim como em 2009 nove municípios receberam um repasse total de $\mathrm{R} \$ 1.210 .534,27$ por intermédio desse mecanismo. 


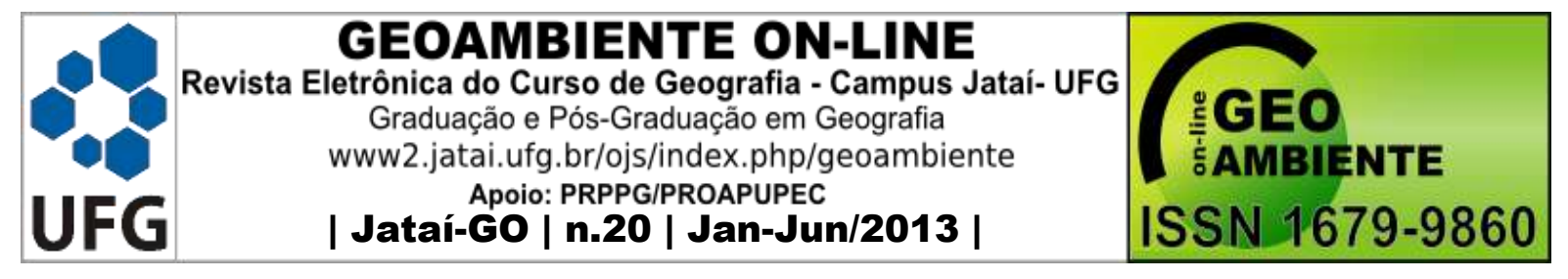

Já em 2011 observou-se uma maior distribuição de recursos, o que é importante para municípios de menor peso populacional como Bonfinópolis e Caturaí, tendo em vista que a rigidez orçamentária dificulta a implantação de obras em tais ambientes. Os recursos destinados ao Ministério das Cidades nesses municípios proporcionaram a construção de calçadas e meio fio. Enquanto municípios como Goiânia concentram a maior parte dos recursos verificou-se que Abadia de Goiás, Brazabrantes, Caldazinha e Guapó não apresentaram nenhum convênio com esse Ministério entre 2009 e 2011, o que nos leva a pensar sobre a estrutura admirativa municipal que por inadimplência, ou por não atender aos requisitos mínimos não estavam aptos a receber tais transferências.

Os valores destinados ao Ministério da Educação tiveram como principal finalidade a melhoria da estrutura física das escolas, compra de equipamentos mobiliários, áudio visuais e materiais para servir de aporte aos professores. Em 2009 o valor total foi de R\$ 4.613.046,25. Os maiores repasses foram observados em Goiânia, Senador Canedo e Bonfinópolis. Outros cinco municípios receberam uma transferência total de $\mathrm{R} \$ 1.136 .892,94$.

Verifica-se que tanto em 2009 quanto 2010, os valores repassados por meio deste Ministério foram os menores ao estabelecer uma comparação entre os Ministérios observados. Em 2010, o valor total das transferências foi de R \$3.023.844,52. Os municípios com maiores repasses foram Goianápolis, Goiânia e Bela Vista de Goiás, respectivamente. Em Goianápolis e Bela Vista de Goiás por meio desse mecanismo foram adquiridos veículos para o transporte escolar de estudantes da rede básica de ensino e em Goiânia para melhoria das condições da educação básica para os alunos com deficiência visual. Já em 2011, os valores totais das transferências foram de $\mathrm{R} \$ 21.938 .675,12$. Os maiores repasses foram para os municípios de Goiânia, Bela Vista de Goiás e Abadia de Goiás. Desse total, Goiânia concentrou R\$ 20.569.149,24, destinados principalmente em infraestrutura, recursos pedagógicos e construção de escolas.

Os demais cinco municípios que firmaram convênios nesse período receberam $\mathrm{R} \$$ $1.369 .525,88$.

Os convênios realizados com o Ministério da Saúde tiveram como principais objetivos as reformas de unidades de saúde, aquisição de equipamentos de uso permanente e materiais de consumo, cursos de treinamento profissional, serviços de aperfeiçoamento dos serviços de urgência e emergência nas unidades de saúde. Em 2009, o valor total repassado aos municípios foi $\mathrm{R} \$ 14.840 .878,38$. Os municípios que obtiveram os maiores valores foram 


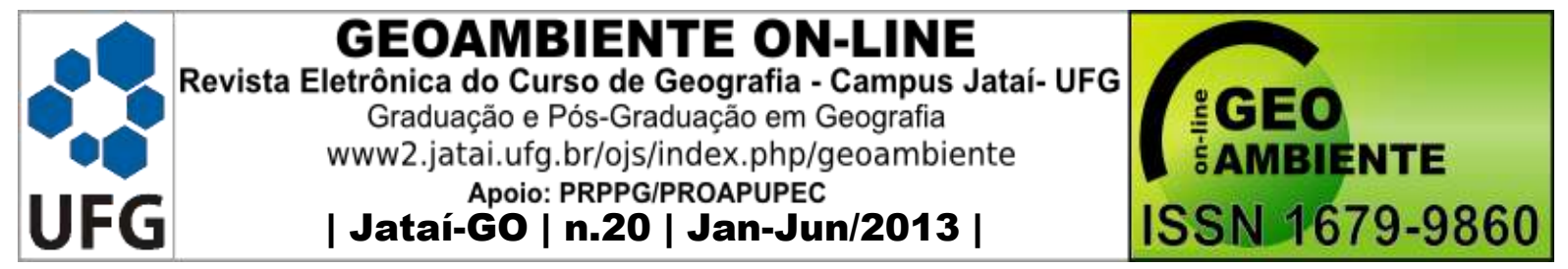

Goiânia, Aparecida de Goiânia e Trindade. Goiânia concentrou 12.351.145,38 do valor total repassado. Os demais municípios concentraram $\mathrm{R} \$ 2.489 .733,00$. Dentre esses municípios, Aparecida de Goiânia se destacou ao utilizar o recurso adquirido na construção de uma maternidade (portal da transparência, 2009). Em 2010, o repasse total foi de R\$ 16.219.131,69. Os maiores repasses foram destinados a Goiânia, Aparecida de Goiânia e Goianápolis. Nesses municípios os principais investimentos realizados foram em materiais de uso permanente nas unidades. O ano de 2011 apresentou os menores valores de repasses se comparado aos anos anteriores. O total foi de $\mathrm{R} \$ 5.985 .022,34$, e os maiores valores destinaram-se a Goiânia, Aparecida de Goiânia e Goianápolis. Esses recursos foram utilizados na aquisição de um veiculo para Goiânia, e de materiais hospitalares, e na melhoria das condições sanitárias domiciliares, com a realização de reformas nos domicílios para atender parte das demandas, de modo a proporcionar melhorias na qualidade sanitária dos domicílios contemplados.

O Ministério do Turismo proporcionou aos municípios a urbanização de parques ecológicos, realização de eventos festivos, revitalização de praças e reforma de parques. Em 2009 os valores totais adquiridos somaram R\$ 15.798.628,77. Apenas seis municípios foram contemplados com transferências nesse mesmo ano e em 2010. Os principais repasses foram destinados a Goiânia, Trindade e Nova Veneza. Em Trindade, o recurso foi destinado à construção de uma passarela a ser utilizada em festas religiosas e na implantação de um portal na entrada da cidade. Em 2010, o valor foi de R\$ 14.682.901,53. O destaque desse ano foi Goiânia, ao concentrar R $\$ 12.032 .255,53$ do valor destinado aos municípios. Os principais objetivos dos repasses para a capital foram para revitalização de praças, e auxilio nas reformas do Parque Mutirama para melhora dos equipamentos turísticos do parque. Em Nova Veneza, os recursos foram destinados à festa gastronômica de cultura italiana realizada anualmente no município.

Na RMG, os municípios que não celebraram nenhum convênio nesse período foram: Brazabrantes, Guapó e Teresópolis. A falta de utilização desse mecanismo nesses municípios decorre de assuntos ligados à estrutura administrativa municipal, a falta de conhecimento sobre a utilização desse instrumento, ou mesmo a escolha dos gestores por não utilizar os convênios como forma de saldar demandas e promover integração com outros municípios da RMG. O acumulo de demandas nesses ambientes e a dificuldade de absorção das demandas nos demais dificulta a instalação de ações conjunturais capazes de promover um 


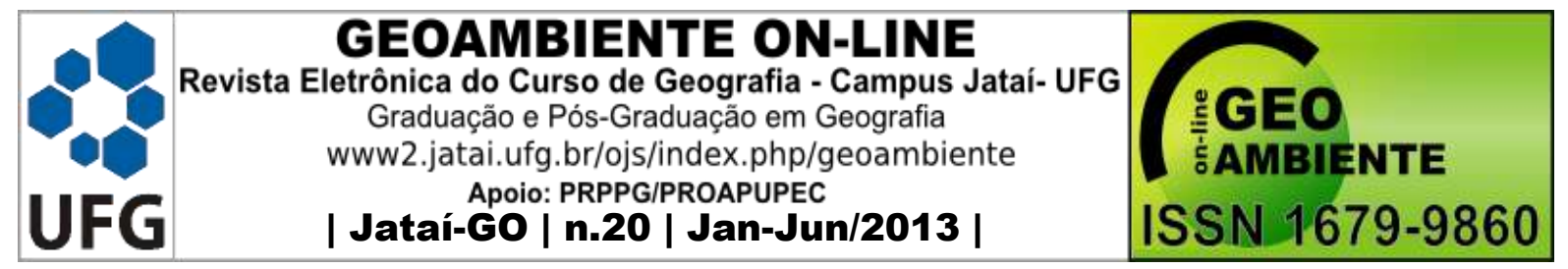

desenvolvimento integrado que seja capaz de proporcionar melhorias na qualidade de vida da população, objetivo inicialmente pensado com a instituição das RMs no Brasil.

\section{CONSIDERAÇÕES FINAIS}

Por meio da exposição de dados secundários e análise bibliográfica foi possível compreender as disparidades existentes entre os municípios da RMG. Esse padrão foi identificado por meio da polarização que Goiânia exerce diante dos demais municípios da RMG ao concentrar grande parte dos equipamentos de serviços, infraestrutura, bem como a estrutura administrativa do Estado. Dos vinte municípios, oito consolidaram convênios de repasses inferiores a 40.000,00 com algum dos Ministérios selecionados, mas que no contexto em que estão inseridos, podem representar importantes melhorias. Entretanto, tais ações são realizadas de forma isolada, impedindo que esses ambientes se tornem integrados entre si. Associando essas informações com a bibliografia consultada nota-se que esse padrão está presente não só na RMG, aparecendo como causa estrutural da organização política administrativa brasileira.

Percebe-se a importância dessa espécie de política pela possibilidade de ação dos governos municipais no espaço, sobretudo o espaço urbano, como já mencionado por Garson (2009) e Lanzana (2010) os recursos para a gestão municipal encontram-se de certa forma “engessados". Desta forma, é importante às pesquisas relacionadas ao planejamento urbano, geografia política e econômica com frequência questionar a distribuição espacial desses recursos, uma vez que, constantemente municípios ficam sem celebrar convênios com nenhum ministério.

Enfim, constata-se que os convênios são importantes instrumentos a serem utilizados para diminuir as disparidades socioeconômicas entre os municípios da RMG, pois permitem aos mesmos:

1. Saldar as demandas por obras de grande porte, tendo em vista a impossibilidade dos gestores municipais de arcar com tais investimentos diante de um cenário de receitas orçamentárias "enrijecidas";

2. A possibilidade de ação conjunta no espaço entre as três esferas governamentais (União, Estados e Municípios), com a presença dos gestores e planejadores como mediadores desse processo; 


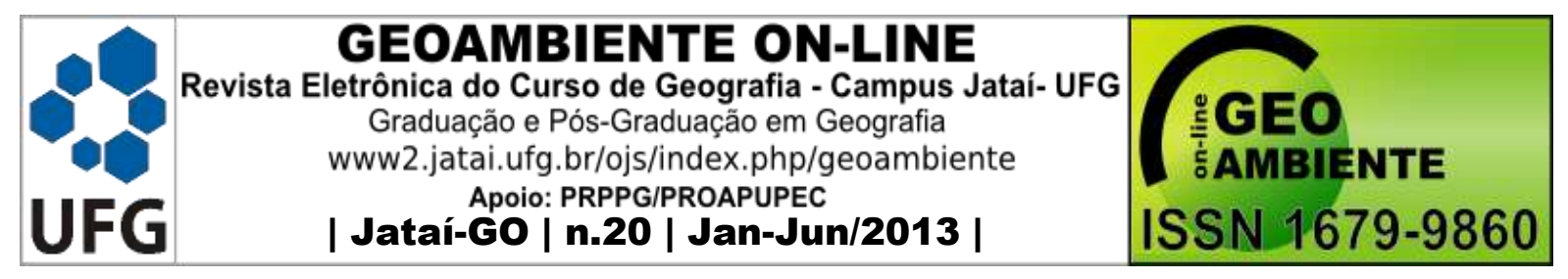

3. Pensar em estratégias para a integração metropolitana, de forma que os municípios com recursos financeiros insuficientes para atender as demandas da população não se tornem dependentes dos equipamentos de outros municípios;

4. Evolução na qualidade de prestação de serviços públicos básicos, adquirindo equipamentos, contratando serviços, ou mesmo, disponibilizando eventos culturais;

5. Descentralização de recursos, desde que os gestores dos demais municípios se adaptem às normativas constitucionais que estabelecem os critérios para consolidação dos convênios.

Enfim, a analise da distribuição espacial dos convênios tem importante contribuição para a agenda de pesquisa geográfica, pois através desse instrumento é possível desenvolver estratégias no âmbito econômico-social espacializadas nos municipios de modo a atender as principais demandas da população.

\section{REFERÊNCIAS}

ARRAIS, Tadeu Alencar. Diversidade territorial e transferências constitucionais para os municípios: considerações sobre a economia regional goiana. Boletim Goiano de Geografia, Goiânia, v.28, n.2, p. 203-216, 2008;

ARRAIS, Tadeu Alencar; SILVA, Cristiano Martins; VIANA, Juheina Lacerda; ALENCAR, Diego Pinheiro. Economia metropolitana pela ótica das receitas municipais: o caso da Região Metropolitana de Goiânia. In: ALMEIDA, Maria Geralda; TEIXEIRA, Karla Annyelly; ARRAIS, Tadeu Alencar (Orgs.). Metrópoles: teoria e pesquisa sobre a dinâmica metropolitana. Goiânia: Cânone Editorial, 2012;

BRASIL. Constituição da República Federativa do Brasil. Brasil.1988;

BRASIL, Ministério do Planejamento. Portaria Interministerial. № 507 de 24 de novembro de 2011. In:

https://www.convenios.gov.br/portal/arquivos/Portaria Interministerial n 50724 Novembro 201 1.pdf. Acesso em 09/05/2012;

CORRÊA, Roberto Lobato. Sobre Agentes Sociais, Escala e Produção do Espaço: Um texto para Discussão. In: CARLOS, Ana Fani Alessandri; SOUZA, Marcelo Lopes; SPOSITO, Maria Encarnação Beltrão (Orgs.). A Produção do Espaço Urbano: Agentes e Processos, Escalas e Desafios. São Paulo: Contexto, 2011; 


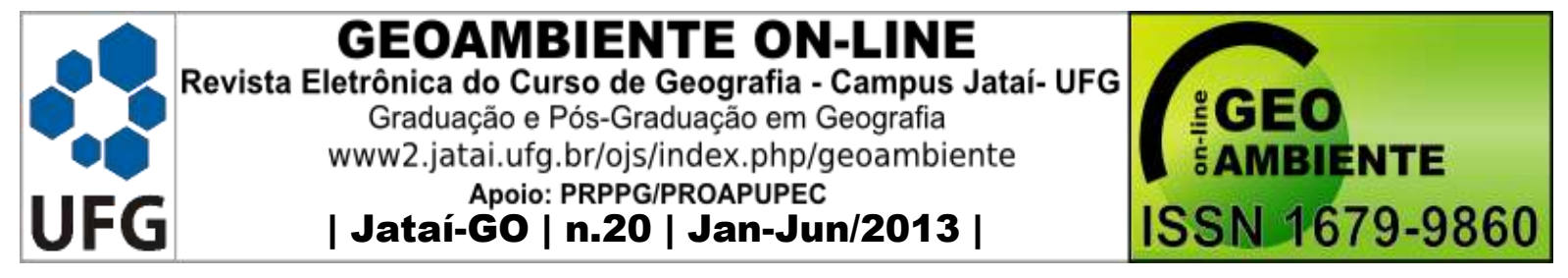

GARSON, Sol. Regiões metropolitanas - Por que não cooperam?. Rio de Janeiro: Editora Letra Capital, 2009;

GOIÁS. Lei complementar $\mathrm{n}^{\circ} 27$, de dezembro de 1999. In: http://www.gabinetecivil.go.gov.br/pagina_leis.php?id=7066. Acesso em 10/05/2012;

Lei complementar $\mathrm{n}^{\circ}$ 78, de março de 2010. In: http://www.gabinetecivil.go.gov.br/pagina_leis.php?id=9457. Acesso em 10/05/2012;

GOUVÊA, Ronaldo Guimarães. A questão metropolitana no Brasil. Rio de Janeiro: Editora FGV, 2005;

HARVEY, David. A justiça social e a cidade. São Paulo: Hucitec, 1980;

IBGE. Censo demográfico 2000. Rio de Janeiro: IBGE, 2000;

IBGE. Censo demográfico 2010. Rio de Janeiro: IBGE, 2010;

LANZANA, Antonio Evaristo Teixeira. Economia Brasileira: fundamentos e atualidade. São Paulo: Editora Atlas, 2010;

LEFEBREV, Henri. A Revolução Urbana. Belo Horizonte: Editora UFMG, 2009;

MACHADO, Gustavo Gomes. Gestão metropolitana e autonomia municipal - dilemas das transferências federativas. Belo Horizonte: PUC Minas, 2009.

\section{Sites consultados:}

http://www.caixa.gov.br/- Acesso em 05/01/2012;

http://www.gabinetecivil.go.gov.br/pagina_leis.php?id=7066- Acesso em 03/01/2012;

http://www.ipea.gov.br/portal/index.php?option=com_content $\& v i e w=\operatorname{article} \& i d=10882$ -

Acesso em 05/01/2012;

http://www.ibge.gov.br/home. Acesso em 04/01/2012;

http://www.planalto.gov.br/ccivil_03/Leis/LCP/Lcp14.htm- acesso em 04/01/2012;

http://www.tcm.go.gov.br/site/index.jsf - Acesso em 09/01/2012;

http://www.portaltransparencia.gov.br/- Acesso em 22/12/2011;

http://www.planalto.gov.br/ccivil_03/leis/L8666cons.htm. Acesso em 15/02/2012;

http://portal.saude.gov.br/portal/saude/visualizar_texto.cfm?idtxt=28726- Acesso em 03/01/2012;

http://www.tesouro.fazenda.gov.br/legislacao/download/estados/IN_STN_1_1997_Convenios /IN_stn_01_15jan1997_convenios.htm- Acesso em 10/02/2012. 